Jurdimas (Jurnal Pengabdian Kepada Masyarakat) Royal

Vol. 4 No. 3, September 2021, hlm. 269 - 274

Available online at https://jurnal.stmikroyal.ac.id/index.php/jurdimas

\title{
PEMANFAATAN SOCIAL ADVERTISING SEBAGAI MEDIA PROMOSI PRODUK PUAN MAKANAN KHAS PALEMBANG
}

\author{
Dewi Sartika ${ }^{1^{*}}$, Imelda Saluza ${ }^{2}$, Roswaty ${ }^{3}$ \\ ${ }^{1}$ Teknik Informatika, Universitas Indo Global Mandiri \\ ${ }^{2}$ Manajemen Informatika, Universitas Indo Global Mandiri \\ ${ }^{3}$ Manajamen, Universitas Indo Global Mandiri \\ email:*dewi.sartika@uigm.ac.id
}

\begin{abstract}
The Gulo Puan Business Group, Bangsal village, Pampangan sub-district, Ogan Komering Ilir district, is a producer of products in the form of gulo-puan, sagon-puan and tapelpuan. After the implementation of the PKMS activity, a product innovation in the form of Mrs. Candy was obtained, while in the PKM activity, a product innovation in the form of Mrs. yogurt was obtained. Based on this, partners have been able to compete with similar business actors because they already have a variety of product variants, both in the form of food and beverages. However, this certainly needs to be strengthened again by utilizing technology to introduce products to the wider community. Social advertising is a promotional media that is carried out through social media. This promotional media is considered far more effective, efficient and on target compared to conventional promotional media such as flyers, banners and so on. Partners in PKMS activities have been able to utilize social media as a marketing medium. Therefore, in PKM activities, the implementing team provides training on the use of social advertising as a promotional media for women's products produced by partners. Based on the results of social advertising that has been done 5 times, the results show that as many as 96,212 accounts were successfully reached, of which $98.2 \%$ were not followers of accounts with demographics $48.2 \%$ male and $51.8 \%$ female. As many as 55\% of the target to open a profile from Mrs. Candy and from a total of 4,018 accounts that liked ads were obtained.
\end{abstract}

Keywords: competitive advantage; puan candy; puan yogurt; social advertising;

Abstrak: Kelompok Usaha Gulo Puan desa Bangsal kecamatan Pampangan kabupaten Ogan Komering Ilir merupakan penghasil produk berupa gulo puan, sagon puan dan tapel puan. Setelah pelaksanaan kegiatan PKMS diperoleh inovasi produk berupa puan candy, sedangkan pada kegiatan PKM diperoleh inovasi produk berupa puan yogurt. Berdasarkan hal tersebut mitra telah mampu bersaing dengan pelaku usaha sejenis karena telah memiliki varian produk puan yang beragam, baik berupa makanan maupun minuman. Namun, hal tersebut tentu perlu diperkuat lagi dengan memanfaatkan teknologi guna mengenalkan produk ke Masyarakat luas. Sosial advertising merupakan media promosi yang dilakukan melalui sosial media. Media promosi ini dianggap jauh lebih efektif, efisien dan tepat sasaran dibandingkan dengan media promosi konvensional seperti selebaran, banner dan sebagainya. Mitra pada kegiatan PKMS telah mampu memanfaatkan sosial media sebagai media pemasaran. Oleh karena itu, pada kegiatan PKM tim pelaksana memberikan pelatihan pemanfaatan sosial advertising sebagai media promosi produk puan yang dihasilkan oleh mitra. Berdasarkan hasil sosial advertising yang telah dilakukan sebanyak 5 kali diperoleh hasil bahwa sebanyak 96.212 akun yang berhasil dijangkau, dimana $98,2 \%$ nya bukan pengikut dari akun dengan demografi $48,2 \%$ berjenis kelamin laki-laki dan $51,8 \%$ perempuan. Sebanyak $55 \%$ dari sasaran membuka profil dari puan candy serta dari total keseluruhan diperoleh 4.018 akun yang menyukai iklan.

Kata kunci: competitive advantage; puan candy; puan yogurt; social advertising 
Available online at https://jurnal.stmikroyal.ac.id/index.php/jurdimas

\section{PENDAHULUAN}

Gulo puan merupakan makanan khas Palembang yang keberadaanya saat ini semakin langka. Dahulu gulo puan terkenal sebagai makanan para bangsawan (Trisnawati, 2020). Gulo puan terbuat dari bahan susu kerbau rawa yang banyak ditemukan di daerah Ogan Komering Ilir. Bahan baku dari makanan ini hampir punah dikarenakan kebakaran hutan yang terjadi pada tahun 2014-2015 lalu mengakibatkan lahan gembala kerbau rawa berkurang. Kelompok Usaha Gulo Puan desa Bangsal merupakan salah satu kelompok usaha penghasil Gulo Puan yang aktif di kabupaten Pampangan Ogan Komering Ilir. Selama ini mereka memproduksi gulo puan setiap hari Jum'at. Pemasaran yang mereka gunakan masih meman-faatkan sistem men to men serta penjualan melalui pihak ketiga. Namun setelah berlangsungnya kegiatan Program Kemitraan Masyarakat Stimulus (PKMS) pada tahun 2019, mitra telah mampu membenahi usahanya. Mulai dari meningkatkan kemasan produk, penambahan produk inovasi berupa permen caramel dengan nama Puan Candy (Sartika, Saluza, \& Roswaty, 2019) serta telah mampu memasarkan produk inovasinya melalui media sosial (Sartika, Saluza, \& Roswaty, 2020b). Berdasarkan hasil yang diperoleh dari kegiatan PKMS, mitra memiliki keinginan untuk terus berkembang dengan menonjolkan produk berbahan dasar Puan selain Gulo Puan yang mereka produksi, yaitu Sagon Puan dan Tapel Puan. Pada tahun 2020 dilangsungkan kegiatan Program Kemitraan Masyarakat (PKM) yang juga didanai oleh Kementrian Riset dan Teknologi/Badan Riset Inovasi Nasional Republik Indonesia (Ristek/BRIN). Pada kegiatan ini kemasan produk-produk Puan ditingkatkan, selain itu mitra dibina untuk mampu membuat produk minuman karena selama ini produk yang dihasilkan mitra masih berupa makanan saja. Produk minuman berbahan dasar Puan diberi nama Puan Yogurt (Sartika, Saluza, \& Roswaty, 2020a). Setelah mitra mampu membenahi produk serta menambah varian produk, selanjutnya mitra perlu pembinaan untuk mampu mengoptimalkan pemanfaatan media sosial yang selama ini digunakan sebagai media pemasaran.

Media sosial saat ini dapat digunakan sebagai media promosi yaitu berupa Social Advertising. Social Advertising memiliki beragam kelebihan dibandingkan media promosi secara konvensional diantaranya mampu menjangkau sasaran dalam waktu singkat, less paper, lebih tepat sasaran, serta minim biaya. Oleh karena itu, social advertising dirasa merupakan media yang tepat untuk memperkenalkan produk-produk Puan yang dihasilkan mitra (Lina \& Permatasari, 2020); (Wulandari \& Darma, 2020).

\section{METODE}

Kegiatan dilakukan melalui metode pelatihan serta pembinaan kepada mitra. Workshop pemanfaatan Social Advertising sebagai media promosi dilaksanakan pada 30 Agustus 2020 di desa Bangsal kabupaten Pampangan Ogan Komering Ilir dengan menerapkan protokol kesehatan. Peserta pada kegiatan ini tidak hanya mitra saja tetapi juga dihadiri oleh perwakilan pemuda pemudi desa Bangsal. Pada kegiatan ini tahapan dan partisipasi antara tim pelaksana dan peserta diantaranya:

1. Tim pelaksana PKM membuat materi pelatihan serta contoh sosial 
advertising. Produk yang diiklankan adalah Tapel Puan

2. Peralatan yang digunakan :
a. Laptop
b. Smartphone
c. Proyektor

3. Tim pelaksana PKM memberikan workshop terkait pemanfaatan sosial advertising sebagai media promosi yang dipraktekkan langsung oleh peserta

4. Setelah kegiatan tim pelaksana PKM membagikan kuisioner kepada peserta guna mengetahui hasil dari kegiatan.

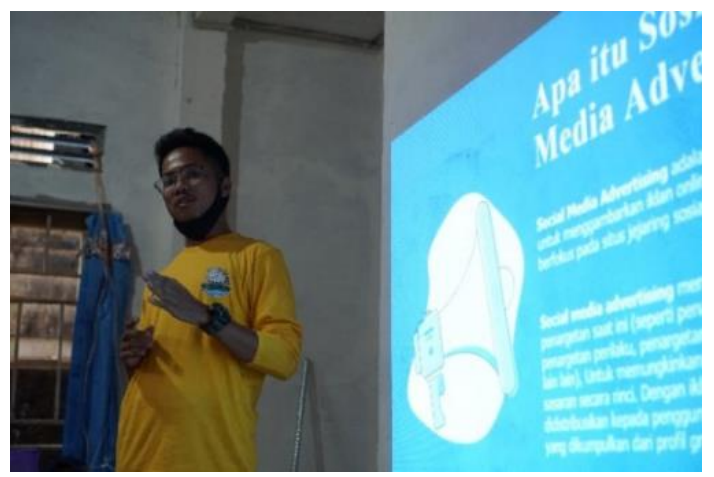

Gambar 1. Mahasiswa Tim Pelaksana PKM memaparkan materi workshop

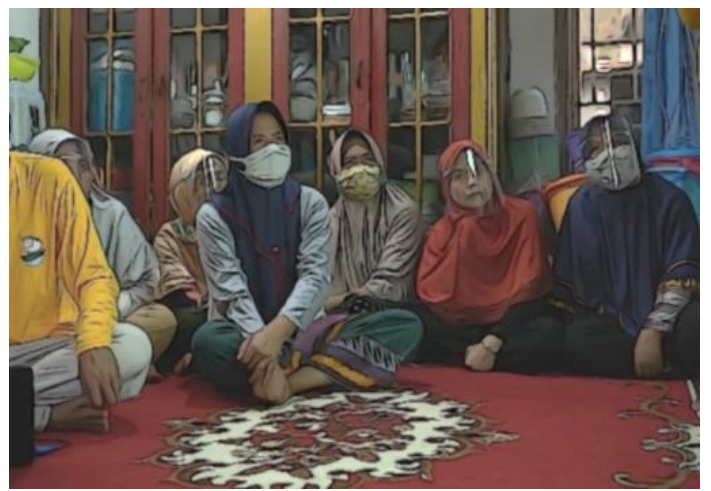

Gambar 2. Peserta workshop

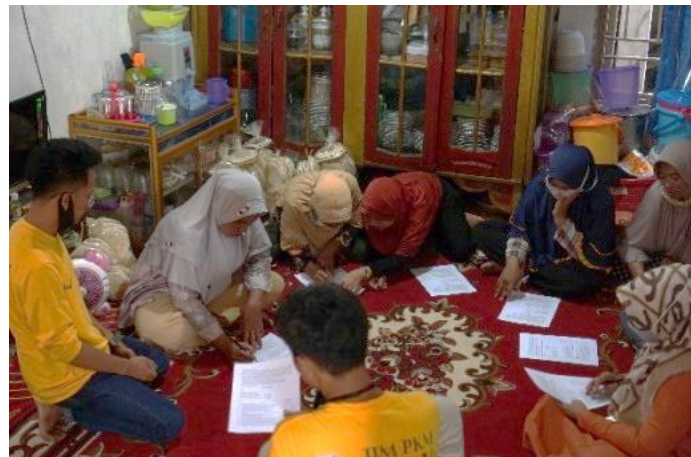

Gambar 3. Pengisian Kuisioner

\section{PEMBAHASAN}

Setelah pelaksanaan kegiatan, tim pelaksana melakukan pembagian kuesioner terhadap peserta pelatihan guna mengetahui pemahaman mitra terhadap materi pelatihan/workshop yang diberikan. Pada kuesioner memuat demografi dari data responden, adapun demografi tersebut antara lain nama, usia, jenjang pendidikan dan kemampuan membaca.

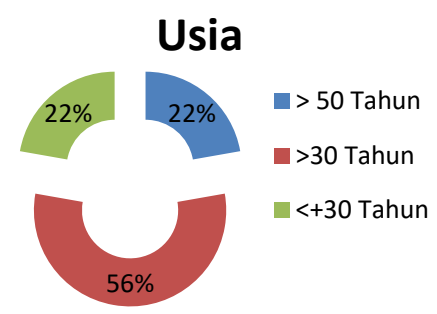

Gambar 4. Demografi Usia Peserta

Gambar 4 menunjukkan bahwa peserta terdiri dari 9 orang dengan tiga kelompok usia yaitu >50 tahun, >30 tahun dan $\leq 30$ tahun. Karena usaha ini dilakukan secara turun temurun sehingga berdasarkan usia maka perlu dilakukan sharing knowledge. 


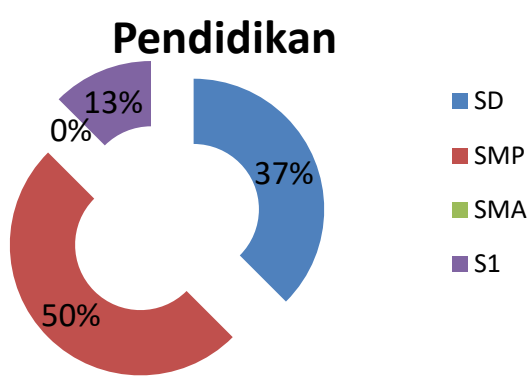

Gambar 5. Demografi Pendidikan Peserta

Gambar 5 menunjukkan demografi mengenai jenjang pendidikan terakhir peserta. Pertanyaan ini diberikan untuk mengetahui tingkat pendidikan dan kemampuan peserta dalam memahami pernyataan yang ada untuk mengukur kualitas kegiatan yang telah dilakukan. Berdasarkan hasil yang diperoleh bahwa masih ada $22 \%$ mitra yang berpendidikan Sekolah dasar (SD), sebanyak 34\% Sekolah Menegah Pertama (SMP), 22\% Sekolah Menegah Atas (SMA) dan 22\% Sarjana (S1). Selanjutnya mitra diberikan pernyataan-pernyataan yang terkait dengan pelatihan yang diberikan. Secara garis besar peserta memberikan respon yang baik terhadap kegiatan pelatihan yang telah diberikan tim pelaksana PKM mengenai media promosi menggunakan sosial media.

Pada akhir kuesioner terdapat pertanyaan terkait media promosi menggunakan sosial media. Pernyataan terdiri dari dua bagian yang pertama mengenai media promosi yang selama ini digunakan sebelum kegiatan pelatihan dan setelah diberikan pelatihan. Dari pernyataan mengenai media promosi respon mitra menunjukkan pada level sangat setuju dan setuju mengenai media promosi yang masih kurang optimal sehingga dibutuhkan kegiatan pelatihan mengenai strategi pemasaran agar penjualan produk optimal. Hasil kegiatan pelatihan mengenai media promosi menunjukkan mitra mampu melakukan promosi menggunakan sosial media.

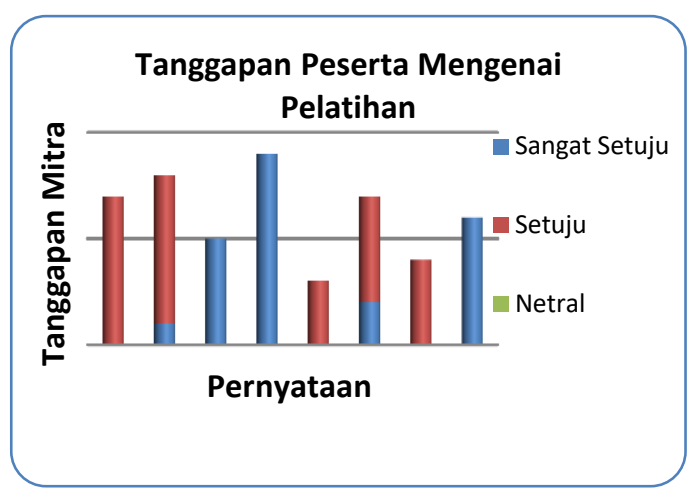

Gambar 6. Tanggapan Peserta Mengenai Pelatihan

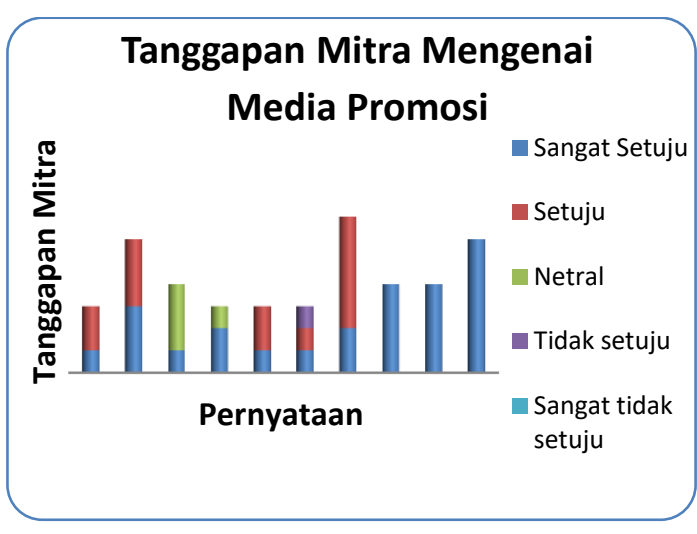

Gambar 7. Tanggapan Peserta Mengenai Media Promosi

Setelah kegiatan berlangsung dilakukan 5 kali percobaan social advertising produk -produk Puan. Hasil percobaan social advertising dapat dilihat pada Tabel 1. 
Available online at https://jurnal.stmikroyal.ac.id/index.php/jurdimas

Tabel 1. Analisis Social Advertising

\begin{tabular}{|c|c|c|c|c|c|}
\hline Adv Ke- & $\begin{array}{c}\text { Akun Yang } \\
\text { dijangkau }\end{array}$ & Pengikut (\%) & $\begin{array}{c}\text { Bukan } \\
\text { Pengikut }(\%)\end{array}$ & $\begin{array}{c}\text { Buka Profil } \\
(\%)\end{array}$ & Like \\
\hline 1 & 3.131 & 2 & 98 & 66 & 801 \\
\hline 2 & 2.619 & 3 & 97 & 31 & 941 \\
\hline 3 & 4.196 & 1 & 99 & 64 & 1.200 \\
\hline 4 & 2.258 & 2 & 98 & 19 & 962 \\
\hline 5 & 84.008 & 1 & 99 & 95 & 114 \\
\hline Total & 96.212 & 1,8 & 98,2 & 55 & 4.018 \\
\hline
\end{tabular}

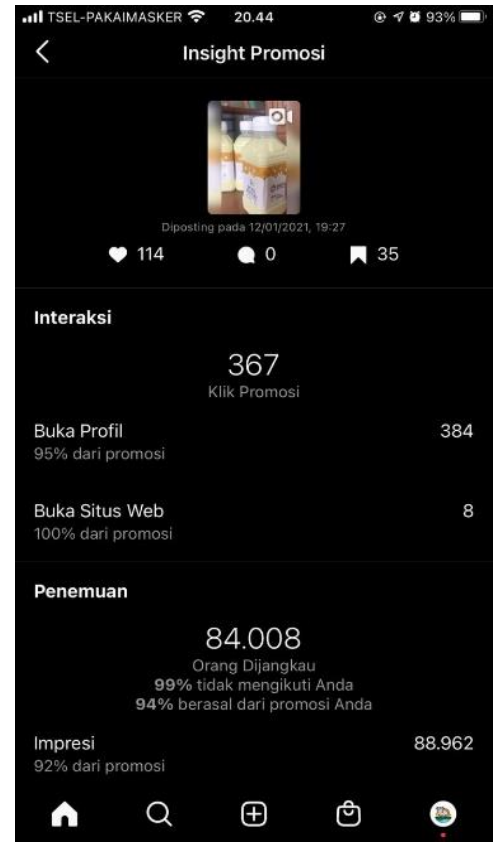

Gambar 8. Hasil Social Advertising ke-5

Berdasarkan hasil social advertising yang telah dilakukan diperoleh hasil bahwa sebanyak 96.212 akun yang berhasil dijangkau, dimana $98,2 \%$ nya bukan pengikut dari akun dengan demografi $48,2 \%$ berjenis kelamin laki-laki dan $51,8 \%$ perempuan. Sebanyak $55 \%$ dari sasaran membuka profil dari puan candy serta dari total keseluruhan diperoleh 4.018 akun yang menyukai iklan.

\section{SIMPULAN}

Berdasarkan hasil kegiatan pelatihan yang telah dilakukan mengenai media promosi menunjukkan bahwa mitra telah mampu melakukan promosi menggunakan media sosial. Social Advertising yang diterapkan guna mempromosikan produk Puan dianggap efektif dan efisien. Hal tersebut ditunjukkan bahwa dari 5 percobaan promosi yang dilakukan berhasil menjangkau 96.212 akun. Hal tersebut tentunya merupakan dampak positif bagi kelompok usaha gulo puan desa bangsal dalam memperkenalkan produknya ke masyarakat luas.

\section{UCAPAN TERIMA KASIH}

Ucapkan terima kasih kepada Kementrian Riset dan Teknologi/Badan Riset Inovasi Nasional Republik Indonesia (Ristek/BRIN) yang telah mendanai kegiatan ini, ucapan terimakasih yang sama juga dihaturkan kepada Kepala desa Bangsal yang telah mendukung kelangsungan kegiatan PKM serta Kelompok Usaha Gulo Puan desa Bangsal selaku mitra yang telah antusias dalam menerima pelatihan dan binaan. 


\section{DAFTAR PUSTAKA}

Arsyah, R. H., \& Juwita, A. I. (2021). Konvergensi Media dalam Pemasaran Produk Kerajinan Masyarakat desa Wisata Pariangan. Jurdimas (Jurnal Pengabdian Kepada Masyarakat) Royal, 4(1), 59-64.

Giyanti, I., Suparti, E., Sunardi, S., \& Sugiarti, S. (2021). Perbaikan Proses Produksi dan Peningkatan Pemasaran pada UKM Putri Timus Di Karanganyar. Jurdimas (Jurnal Pengabdian Kepada Masyarakat) Royal, 4(2), 127-134.

Lina, L. F., \& Permatasari, B. (2020). Social Media Capabilities dalam Adopsi Media Sosial Guna Meningkatkan Kinerja UMKM. Jembatan: Jurnal Ilmiah Manajemen, 17(2), 227-238. doi: 10.29259/jmbt.v17i2.12455

Sartika, D., Saluza, I., \& Roswaty. (2019). Branding Produk Gulo Puan dan Produk Inovasi Gulo Puan ( Puan Candy ) sebagai Makanan Khas Palembang dari Ogan Komering Ilir ( OKI ). Seminar Nasional II Hasil
Litbangyasa Industri, 212-220.

Sartika, D., Saluza, I., \& Roswaty. (2020a). Inovasi produk olahan susu kerbau rawa (puan) menjadi minuman fermentasi. Seminar Nasional AVoER XII, (November), 18-19.

Sartika, D., Saluza, I., \& Roswaty. (2020b). Penerapan Bauran Pemasaran (Marketing Mix) Sebagai Strategi Pemasaran Produk Gulo Puan Desa Bangsal. Jurnal Pengabdian Kepada Masyarakat APTEKMAS, 3(2), 47-54.

Trisnawati, L. (2020). Cerita Gulo Puan, Dulunya Makanan Bangsawan.

Wulandari, L. P. A., \& Darma, G. S. (2020). Advertising Effectiveness in Purchasing Decision on Instagram. Journal of Business on Hospitality and Tourism, 6(2), 381. doi: 10.22334/jbhost.v6i2.220.

Yenni, Y., Utnasari, I., \& Rahmawati, M. (2021). Sosialisasi Pemanfaatan Teknologi Informasi Internet Berbasis Media Sosial Sebagai Usaha dan Transaksi. Jurdimas (Jurnal Pengabdian Kepada Masyarakat) Royal, 4(1), 1-6. 